XXVII Cangressa de Iniciaçãa Cientifica Unicamp

16 a 18 de outubro de 2019 - Campinas |Brasil

\title{
Ler para escrever: da leitura dos textos da prova à escrita de texto-base para palestra no
} vestibular Unicamp 2018

\section{Mariana Hernandes Porto*, Márcia Rodrigues de Souza Mendonça.}

\section{Resumo}

Esta pesquisa de Iniciação Científica tem o objetivo de investigar os modos como os candidatos ao vestibular Unicamp utilizam o(s) texto(s) de leitura da prova para construir os gêneros solicitados, mapeando possíveis relações entre operações de leitura e de escrita.

\section{Palavras-chave:}

Escrita, Vestibular, Paráfrase

\section{Introdução}

Sendo a leitura um dos aspectos centrais a serem avaliados no vestibular Unicamp (COMVEST, 2018), busca-se aqui mapear possíveis relações entre operações de leitura e de escrita, tomando como foco o mecanismo da paráfrase, compreendido como a atividade efetiva de reformulação pela qual o sujeito reconstrói o conteúdo de um texto-fonte sob a forma de um texto segundo (FUCHS, 1985). Esse é um processo que necessariamente se dá a partir de uma interpretação prévia e individual do texto-fonte, seguida pela sua reconstrução em um novo texto.

A amostra é constituída de 100 provas de redação do Texto 1 e o corpus foi composto por 54 textos - do gênero texto-base para palestra, sendo esta sobre o impacto da pós-verdade - do vestibular Unicamp 2018, oriundas de cursos de concorrência alta, média e baixa.

\section{Resultados e Discussão}

Foi realizado um mapeamento que identifica quais são $e$ de que maneira se constituem as principais formas de trazer, para os textos produzidos naquela proposta do vestibular, os pontos centrais dos enunciados veiculados nos textos de leitura apresentados na prova do vestibular Unicamp 2018. Mobilizou-se o conceito de proposição, que liga-se à ideia de subdivisão do enunciado em duas partes constitutivas, o dictum - proposição, parte descritiva - e o modus - não proposição, modalidade, ponto de vista do sujeito falante sobre o dito - (LYONS, 1977). Neste mapeamento é levado em consideração (i) qual é a proposição; (ii) se o enunciado é simples (parte de um única proposição) ou complexo (envolve uma ou mais proposições); (iii) qual é a correspondência (DUARTE, 2003) entre o enunciado do texto produzido e aquele do texto-fonte: total (mantendo inalterada a estrutura e léxico), parcial (parcialmente alterando a estrutura e léxico) ou autoral (reconstruindo a proposição a partir da interpretação individual), além de considerar se o enunciado do texto produzido faz uso de referência, através de marcas textuais, como aspas, àquele do texto-fonte. Foram então definidas 6 categorias para as proposições, sendo estas se referindo a:

1. O fato de pós-verdade ter sido eleita a palavra do ano pela Universidade de Oxford;

2. A definição do uso do termo pós-verdade;

3. Os exemplos de fake news;
4. A ideia de que fake news fizeram parte de estratégias de radicalizar posicionamentos de eleitorados;

5. O papel das redes sociais na pós-verdade;

6. A menções ao cartoon do Texto 2

Além da relação de distribuição de proposições por redação, analisou-se o número de ocorrências por categoria de proposição, por arquivo, por tipo de entrada (Tabela 1) e por tipo de correspondência (Tabela 2). Das 54 redações analisadas, o total de ocorrências de proposições foi de 167.

Tabela 1. Tipos de proposições.

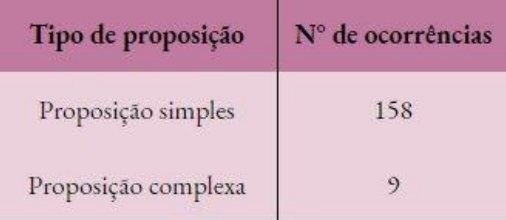

Tabela 2. Tipos de correspondência.

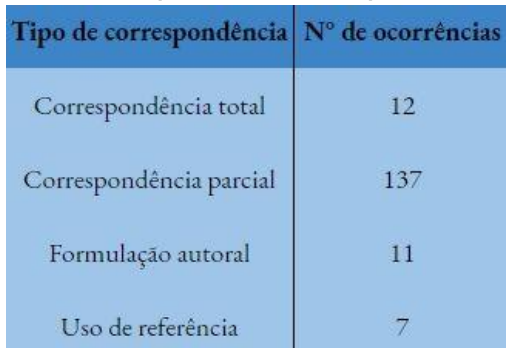

\section{Conclusões}

De acordo com as hipóteses iniciais do projeto, os resultados encontrados até 0 presente momento apontam a predominância de proposições que se referem a exemplos do texto-fonte, bem como um número superior de proposições de correspondência parcial sobre aquelas de correspondência total ou de formulação autoral. Tais resultados preliminares parecem indicar que os candidatos preferiram, nesta proposta de escrita, parafrasear os textos de leitura, mas o fazem de forma simples.

COMVEST, Manual do Candidato 2019. Coordenadoria Executiva dos Vestibulares da Unicamp. [Campinas]: Prol, 2018a. Caderno de questões 2018. Coordenadoria Executiva dos Vestibulares da Unicamp. [Campinas]: Prol, 2018b DUARTE, P. M. Elementos para o estudo da paráfrase. Revista Letras, 59, 2003

FUCHS, C. A paráfrase linguística: equivalência, sinonímia ou reformulação? Cadernos de Estudos linguísticos, 8, 129-134. 1985

LYONS, J., Semantics. Cambridge University Press, 1977. 